\title{
The Association between Influenza Vaccination and COVID-19 and Its Outcomes: A Systematic Review and Meta-Analysis of Observational Studies
}

\author{
Ruitong Wang ${ }^{1}$, Min Liu $^{1}$ and Jue Liu ${ }^{1,2,3, *(\mathbb{D})}$ \\ 1 Department of Epidemiology and Biostatistics, School of Public Health, Peking University, \\ Beijing 100191, China; wangruitong@pku.edu.cn (R.W.); liumin@bjmu.edu.cn (M.L.) \\ 2 Institute for Global Health and Development, Peking University, Beijing 100191, China \\ 3 Key Laboratory of Reproductive Health, National Health Commission of the People's Republic of China, \\ Beijing 100083, China \\ * Correspondence: jueliu@bjmu.edu.cn
}

Citation: Wang, R.; Liu, M.; Liu, J. The Association between Influenza Vaccination and COVID-19 and Its Outcomes: A Systematic Review and Meta-Analysis of Observational Studies Vaccines 2021, 9, 529. https:// doi.org/10.3390/vaccines9050529

Academic Editor:

Luis Martinez-Sobrido

Received: 17 April 2021

Accepted: 17 May 2021

Published: 20 May 2021

Publisher's Note: MDPI stays neutral with regard to jurisdictional claims in published maps and institutional affiliations.

Copyright: (c) 2021 by the authors. Licensee MDPI, Basel, Switzerland. This article is an open access article distributed under the terms and conditions of the Creative Commons Attribution (CC BY) license (https:// creativecommons.org/licenses/by/ $4.0 /)$.

\begin{abstract}
Influenza could circulate in parallel with COVID-19. In the context of COVID-19, some studies observed inverse associations between influenza vaccination and SARS-CoV-2 infection and clinical outcomes, while others did not. We conducted a meta-analysis to assess the association between influenza vaccination and SARS-CoV-2 infection and clinical outcomes, aiming to provide evidence for COVID-19 prevention and vaccination promotion. We searched four databases from inception to $10 \mathrm{March}$, 2021. Random effects and fixed effects models were used to pool odds ratios (ORs) and adjusted estimates with 95\% confidence intervals (CIs). We used funnel plots to evaluate the publication bias, I2 statistics to evaluate the heterogeneity, and conducted subgroup analyses. Sixteen observational studies involving 290,327 participants were included. Influenza vaccination was associated with a lower risk of SARS-CoV-2 infection (pooled adjusted OR: 0.86, 95\%CI: 0.81-0.91), while not significantly associated with adverse outcomes (intensive care: adjusted OR 0.63, 95\%CI: 0.22-1.81; hospitalization: adjusted OR 0.74, 95\%CI: 0.51-1.06; mortality: adjusted OR $0.89,95 \%$ CI: 0.73-1.09). Our findings suggest that influenza vaccination is associated with a lower risk of SARS-CoV-2 infection. It is crucial for policy makers to implement strategies on influenza vaccination, for it may also have benefits for COVID-19 prevention.
\end{abstract}

Keywords: influenza vaccination; COVID-19; infection; outcome; meta-analysis

\section{Introduction}

The coronavirus disease (COVID-19) is an acute respiratory infectious disease that was declared a global public health emergency by the World Health Organization (WHO) in January 2020 [1]. The global pandemic has hitherto caused 119 million cases of infection and 2 million cases of death [1], and imposed tremendous burden on global health and worldwide economics. Thus, effective cures and vaccines are imperatively needed to curtail the pandemic and decrease mortality. Seasonal influenza occurs from fall to spring annually, characterized by the circulation of influenza A or B virus [2]. Influenza and its complications could lead to increased worldwide mortality and morbidity, which remain a public health threat.

Due to the seasonality of influenza outbreaks and the continuous prevalence of COVID19, influenza could circulate in parallel with COVID-19, which largely increases the potential risk of co-infection. Though little is known about the epidemiology and clinical outcomes of co-infection, extant literature has found that the co-infection with influenza A virus enhances the infectivity of COVID-19 in a broad range of cell types [3], whereas co-infected patients seem to present similar clinical symptoms and radiological images compared with patients infected with COVID-19 alone [4,5]. In the context of the COVID19 pandemic, the dual infection of influenza and COVID-19 could bring extra burden 
to health care services by utilizing limited medical resources, increasing the difficulty of treatment and the uncertainty of prognosis. Annual influenza vaccination has long been recommended by WHO to prevent influenza, especially to the high-risk populations with disproportionate infection and severe complications, such as older adults (aged $>65$ years) and pregnant women [6]. To date, no highly effective pharmaceutical treatment is available against COVID-19 [7]. Though COVID-19 vaccines remain the most effective long-term solution to combat COVID-19 pandemic [8], the overall effectiveness and safety of the licensed COVID-19 vaccines remain to be fully evaluated based on real-world evidence.

According to a previous study by Wolff [9], which investigated influenza vaccinerelated virus interference by specific respiratory viruses (e.g., coronavirus, human bocavirus, and adenovirus), there was an increased odd of coronavirus in individuals receiving influenza vaccination. This finding raised much concerns of the possible relationship between influenza vaccination and coronavirus, especially in the COVID-19 pandemic. In addition, as COVID-19 and influenza are both respiratory infectious diseases caused by enveloped RNA viruses that share similarities in transmission routes and clinical characteristics [10], more and more researchers began to seek for relationships between SARS-CoV-2 infection and influenza immunity. Based on the assumptions, Del Riccio et al. [11] conducted a systematic review and found that there was overall no evidence to suggest a negative impact of influenza vaccination on SARS-CoV-2 related infections, illness, or deaths, while some of the included studies even reported significantly inverse associations. Though some of the recent studies have found that influenza vaccine uptake was negatively associated with COVID-19 incidence [12,13], severity [13,14], and mortality [13,15], others showed no evidence of such associations [16-18]. Therefore, a systematic review and meta-analysis of the association between influenza vaccination and SARS-CoV-2 infection and its outcomes is needed to provide conclusive evidence.

In the dual epidemics of COVID-19 and influenza, influenza vaccination has a more significant implication than ever for preventing both influenza and COVID-19. It is especially of great necessity for vulnerable populations to receive influenza vaccination. Given the limited data of COVID-19 vaccine effectiveness among vulnerable groups, as well as the necessity of influenza vaccination in the context of COVID-19, and the lack of conclusive evidence of influenza vaccination's effect on SARS-CoV-2 infection and its clinical outcomes, there is a need to systematically assess the potential association between influenza vaccination and COVID-19. In this regard, we conducted a systematic review and meta-analysis to assess the overall association between influenza vaccination and SARS-CoV-2 infection and clinical outcomes, aiming to provide evidence for public health decision makers to develop COVID-19 preventive measures and provide implications for vaccination promotion.

\section{Materials and Methods}

\subsection{Data Sources and Search Strategy}

We searched PubMed, Embase, Web of Science, and Cochrane Library for eligible studies published from June 1971 to 10 March, 2021 using the following search terms: ('flu' OR 'influenza') AND ('COVID-19' OR 'SARS-CoV-2' OR 'coronavirus') AND ('vaccination' OR 'vaccine'). We used EndNote 20 software to manage records, exclude duplicates, and screen abstracts and titles. This study was conducted in accordance with the Preferred Reporting Items for Systematic Reviews and Meta-Analyses (PRISMA) guidelines and the Meta-analysis of Observational Studies in Epidemiology (MOOSE) guidelines. We prospectively submitted the systematic review protocol for registration on PROSPERO (registration ID: CRD42021244442).

\subsection{Data Sources and Search Strategy}

We basically included observational studies that examined the association between influenza vaccination and SARS-CoV-2 infection or reported the association between influenza vaccination and clinical outcomes among SARS-CoV-2 infected populations. 
The following studies were excluded: (1) irrelevant to the subject of the meta-analysis, such as studies that did not use influenza vaccination as the exposure or did not report the outcomes; (2) insufficient data to calculate the odds ratio (OR) or select the adjusted estimates (aRR or aOR) on the association between influenza vaccination and SARS-CoV-2 infection and outcomes; (3) duplicate studies or overlapping participants; (4) reviews, editorials, conference papers, case reports or animal experiments; (5) studies that did not mention the identification of COVID-19. For example, the confirmed diagnosis of COVID19 via reverse-transcription polymerase chain reaction (rt-PCR) test, serologic test, or other means were not mentioned in the text; and (6) studies that did not clarify the ascertainment of influenza vaccination (health system record/self-report).

Studies were identified by two investigators (R.W. and J.L.) independently following the criteria above, while discrepancies were resolved with a third investigator (M.L.).

\subsection{Quality Assessment}

We evaluated the risk of bias using the Newcastle-Ottawa quality assessment scale for cohort studies and case-control studies [19], while the methodological quality of crosssectional studies was assessed using the checklist recommended by Agency for Healthcare Research and Quality (AHRQ) [20]. Cohort studies and case-control studies were classified as having low ( $\geq 7$ stars), moderate (5-6 stars), and high ( $\leq 4$ stars) risk of bias with an overall quality score of 9 stars. For cross-sectional studies, we assigned each item of the AHRQ checklist a score of 1 (answered "yes") or 0 (answered "no" or "unclear"), and summarized scores across items to generate an overall quality score that ranged from 0 to 11. Low, moderate, and high risk of bias were identified as having a score of $8-11,4-7$ and $0-3$, respectively. Two investigators (R.W. and J.L.) independently assessed study quality, with disagreements resolved by a third investigator (M.L.).

\subsection{Data Extraction}

The primary outcome was the association between influenza vaccination and SARSCoV-2 infection, and the secondary outcome was the association between influenza vaccination and clinical outcomes of SARS-CoV-2 infection. The following data were extracted independently from the selected studies: (1) basic information of the studies, including first author, publication year, variables adjusted in the analysis and study design; (2) characteristics of the study population, including sample sizes, age groups, or regions; (3) seasons for influenza vaccination of the exposed group; (4) primary outcomes: the number of SARS-CoV-2 infected and non-infected people and by vaccination status (vaccinated or unvaccinated); (5) secondary outcomes: the number of influenza vaccinated and unvaccinated people and by clinical outcomes of SARS-CoV-2 infection (e.g., hospitalization, mortality, and intensive care); and (6) adjusted estimates (aRR or aOR) with $95 \% \mathrm{CI}$ that were relevant to the primary or secondary outcomes. If a study reported the crude estimates or adjusted estimates of different influenza seasons, only the estimates of the most recent influenza season were included.

\subsection{Data Synthesis and Statistical Analysis}

We performed a meta-analysis to pool data from observational studies and assessed the overall associations between influenza vaccination and COVID-19 by clinical outcomes (infected vs. uninfected, hospitalization vs. non-hospitalization, death vs. alive, intensive care vs. non-intensive care). Random effects and fixed effects models were used to pool the crude ORs and adjusted ORs across studies separately. The pooled estimates were deemed significant when the according 95\%CIs did not pass through zero and the $p$ value was less than 0.05 .

We conducted subgroup analyses to investigate the possible sources of heterogeneity by using study designs, sample sizes, and regions as grouping variables. We used the $Q$ test to conduct subgroup comparisons and variables were considered significant between subgroups if the subgroup difference $p$ value was less than 0.05 . Sensitivity analyses were 
performed by omitting one study at a time to assess studies with notable impact and examine the robustness of the overall effect. Funnel plots and Egger's tests were used to assess publication bias. We analyzed data using Stata version 16.0 and $\mathrm{R}$ version 4.0.2.

\section{Results}

\subsection{Study Selection and Study Characteristics}

A total of 2895 records were retrieved from the four databases and 1467 duplicates were excluded. After screening titles and abstracts, we excluded 1387 reviews, conference papers, animal experiments, case reports, and other studies irrelevant to the subject or published before December 2019. Among the 41 articles assessed based on full texts, 25 articles were excluded for lacking specific data or did not meet the inclusion criteria. A total of 16 studies were finally included in the review (12 studies on the association between influenza vaccination and SARS-CoV-2 infection [16,18,21-30], 6 on the association between influenza vaccination and COVID-19 clinical outcomes [10,17,22,26,31,32], 2 studies containing data on both the associations $[22,26]$. Nine of the 12 studies on the association between influenza vaccination and SARS-CoV-2 infection contained adjusted estimates. One [21] of the 16 studies has moderate risk of bias, while the others have low risk of bias. The primary outcome (the association between influenza vaccination and SARS-CoV-2 infection) comprised a total of 208,132 people ( 72,820 vaccinated and 135,112 unvaccinated). The secondary outcome (the association between influenza vaccination and clinical outcomes of SARS-CoV-2 infection) comprised a total of 82,684 COVID-19 patients and was assessed by different outcomes (mortality, intensive care, and hospitalization). The study selection procedure is shown in Figure 1. The baseline characteristics of the included studies are listed in Table 1 (primary outcome) and Table 2 (secondary outcome). The adjusted variables of the included studies were basically age, sex, comorbidities, prescribed medications and smoking status, but were not the same across studies (see Tables 1 and 2). 
Table 1. Baseline characteristics of the 12 included studies that assessed the association between influenza vaccination and SARS-CoV-2 infection.

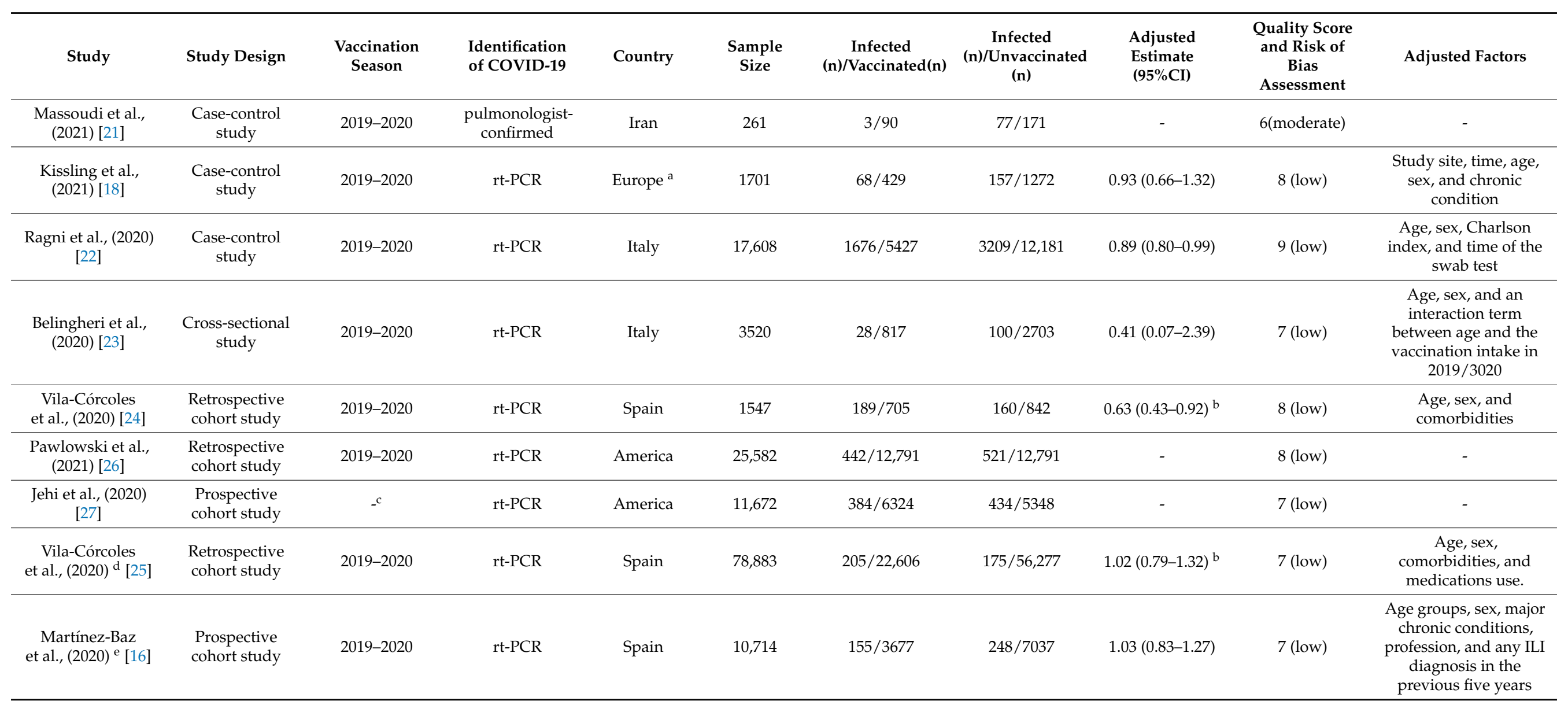


Table 1. Cont.

\begin{tabular}{|c|c|c|c|c|c|c|c|c|c|c|}
\hline Study & Study Design & $\begin{array}{l}\text { Vaccination } \\
\text { Season }\end{array}$ & $\begin{array}{l}\text { Identification } \\
\text { of COVID-19 }\end{array}$ & Country & $\begin{array}{l}\text { Sample } \\
\text { Size }\end{array}$ & $\begin{array}{c}\text { Infected } \\
\text { (n)/Vaccinated(n) }\end{array}$ & $\begin{array}{c}\text { Infected } \\
\text { (n)/Unvaccinated } \\
\text { (n) }\end{array}$ & $\begin{array}{l}\text { Adjusted } \\
\text { Estimate } \\
(95 \% \mathrm{CI})\end{array}$ & $\begin{array}{c}\text { Quality Score } \\
\text { and Risk of } \\
\text { Bias } \\
\text { Assessment }\end{array}$ & Adjusted Factors \\
\hline $\begin{array}{l}\text { Noale et al., } \\
\text { (2020) [28] }\end{array}$ & $\begin{array}{l}\text { Cross-sectional } \\
\text { study }\end{array}$ & 2019-2020 & rt-PCR & Italy & 6680 & $562 / 2246$ & $1114 / 4434$ & $0.89(0.78-1.01)$ & 8 (low) & $\begin{array}{l}\text { Age, sex, education, } \\
\text { area of residence, } \\
\text { self-reported } \\
\text { comorbidities, and } \\
\text { smoking status }\end{array}$ \\
\hline $\begin{array}{l}\text { Green et al., } \\
\text { (2020) [29] }\end{array}$ & $\begin{array}{l}\text { Cross-sectional } \\
\text { study }\end{array}$ & 2019-2020 & $\mathrm{rt}-\mathrm{PCR}$ & Israel & 22,563 & $244 / 4711$ & $1580 / 17,852$ & $0.79(0.67-0.98)$ & 9 (low) & $\begin{array}{l}\text { Age, ethnic, smoking } \\
\text { status, socioeconomic } \\
\text { status, and } \\
\text { comorbidities }\end{array}$ \\
\hline $\begin{array}{l}\text { Conlon et al., } \\
\text { (2021) [30] }\end{array}$ & $\begin{array}{l}\text { Retrospective } \\
\text { cohort study }\end{array}$ & 2019-2020 & rt-PCR & America & 27,201 & $525 / 12,997$ & $693 / 14,204$ & $0.76(0.68-0.86)$ & 8 (low) & $\begin{array}{l}\text { Ethnicity, race, sex, } \\
\text { age, BMI, Elixhauser } \\
\text { score, smoking status, } \\
\text { and comorbidities }\end{array}$ \\
\hline
\end{tabular}

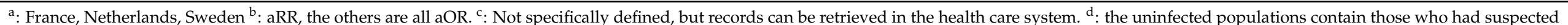
infection but were not tested. ${ }^{e}$ : the uninfected populations contain those who were not tested with no suspected infection. rt-PCR, reverse transcription-polymerase chain reaction.

Table 2. Baseline characteristics of the six included studies that assessed the association between influenza vaccination and SARS-CoV-2 outcomes.

\begin{tabular}{|c|c|c|c|c|c|c|c|c|c|c|}
\hline Study & Study Design & $\begin{array}{l}\text { Vaccination } \\
\text { Season }\end{array}$ & $\begin{array}{l}\text { Identification } \\
\text { of COVID-19 }\end{array}$ & Country & $\begin{array}{l}\text { Sample } \\
\text { Size }\end{array}$ & $\begin{array}{c}\text { Events } \\
\text { (n)/Vaccinated(n) }\end{array}$ & $\begin{array}{c}\text { Events } \\
\text { (n)/Unvaccinated } \\
\text { (n) }\end{array}$ & $\begin{array}{l}\text { Adjusted } \\
\text { Estimate } \\
(95 \% \mathrm{CI})\end{array}$ & $\begin{array}{c}\text { Quality Score } \\
\text { and Risk of } \\
\text { Bias } \\
\text { Assessment }\end{array}$ & Adjusted Factors \\
\hline \multicolumn{11}{|c|}{ Intensive Care } \\
\hline $\begin{array}{l}\text { Pawlowski et al., } \\
\text { (2020) [26] }\end{array}$ & $\begin{array}{l}\text { Retrospective } \\
\text { cohort study }\end{array}$ & 2019-2020 & $\mathrm{rt}-\mathrm{PCR}$ & America & 959 & $15 / 441$ & $16 / 518$ & - & 8 (low) & - \\
\hline $\begin{array}{l}\text { de la Cruz Conty et al., } \\
(2021)^{\text {a }}[17]\end{array}$ & $\begin{array}{l}\text { Prospective } \\
\text { cohort study }\end{array}$ & $-b$ & rt-PCR & Spain & 1150 & $7 / 438$ & $15 / 712$ & - & 7 (low) & - \\
\hline Yang et al., (2021) [32] & $\begin{array}{l}\text { Retrospective } \\
\text { cohort study }\end{array}$ & 2019-2020 & $\mathrm{rt}-\mathrm{PCR}$ & America & 2005 & $3 / 214$ & $133 / 1791$ & $0.30(0.07-0.85)$ & 8 (low) & $\begin{array}{c}\text { Age, sex } \\
\text { race/ethnicity, } \\
\text { hypertension, and } \\
\text { comorbidities }\end{array}$ \\
\hline
\end{tabular}


Table 2. Cont.

\begin{tabular}{|c|c|c|c|c|c|c|c|c|c|c|}
\hline Study & Study Design & $\begin{array}{l}\text { Vaccination } \\
\text { Season }\end{array}$ & $\begin{array}{l}\text { Identification } \\
\text { of COVID-19 }\end{array}$ & Country & $\begin{array}{l}\text { Sample } \\
\text { Size }\end{array}$ & $\begin{array}{c}\text { Events } \\
\text { (n)/Vaccinated(n) }\end{array}$ & $\begin{array}{c}\text { Events } \\
\text { (n)/Unvaccinated } \\
\text { (n) }\end{array}$ & $\begin{array}{l}\text { Adjusted } \\
\text { Estimate } \\
(95 \% \mathrm{CI})\end{array}$ & $\begin{array}{c}\text { Quality Score } \\
\text { and Risk of } \\
\text { Bias } \\
\text { Assessment }\end{array}$ & Adjusted Factors \\
\hline \multicolumn{11}{|c|}{ Hospitalization } \\
\hline $\begin{array}{l}\text { Pawlowski et al., } \\
(2020)[26]\end{array}$ & $\begin{array}{l}\text { Retrospective } \\
\text { cohort study }\end{array}$ & 2019-2020 & rt-PCR & America & 959 & $74 / 441$ & $78 / 518$ & - & 8 (low) & - \\
\hline Yang et al., (2021) [32] & $\begin{array}{l}\text { Retrospective } \\
\text { cohort study }\end{array}$ & 2019-2020 & rt-PCR & America & 2005 & $43 / 214$ & $747 / 1791$ & $0.41(0.28-0.60)$ & 8 (low) & $\begin{array}{c}\text { Age, sex } \\
\text { race/ethnicity, } \\
\text { hypertension, and } \\
\text { comorbidities }\end{array}$ \\
\hline Ragni et al., (2020) [22] & $\begin{array}{l}\text { retrospective } \\
\text { cohort study }\end{array}$ & 2019-2020 & rt-PCR & Italy & 17,608 & - & - & $0.84(0.83-1.29)^{\mathrm{d}}$ & 7 (low) & $\begin{array}{c}\text { Age, sex, Charlson } \\
\text { index, and time of the } \\
\text { swab test }\end{array}$ \\
\hline $\begin{array}{c}\text { Wilcox et al., (2021) } \\
\text { [31] }\end{array}$ & $\begin{array}{l}\text { retrospective } \\
\text { cohort study }\end{array}$ & 2019-2020 & rt-PCR & England & 6921 & $1166 / 2613$ & $1584 / 4308$ & $0.85(0.75-0.97)$ & 8 (low) & $\begin{array}{c}\text { Age, sex, BMI, } \\
\text { socioeconomic status, } \\
\text { smoking status, frailty } \\
\text { score, comorbidities, } \\
\text { and the number of } \\
\text { prescribed } \\
\text { medications }\end{array}$ \\
\hline \multicolumn{11}{|c|}{ Mortality } \\
\hline Fink et al., (2020) [10] & $\begin{array}{l}\text { Retrospective } \\
\text { cohort study }\end{array}$ & $-b$ & $\begin{array}{c}\text { Clinical } \\
\text { diagnosis }^{c}\end{array}$ & Brazil & 53,752 & - & - & $0.84(0.77-0.91)$ & 7 (low) & $\begin{array}{l}\text { Age, sex, race, } \\
\text { educational level, } \\
\text { treatment facility, and } \\
\text { comorbidities }\end{array}$ \\
\hline Ragni et al., (2020) [22] & $\begin{array}{l}\text { retrospective } \\
\text { cohort study }\end{array}$ & 2019-2020 & rt-PCR & Italy & 17,608 & - & - & $1.14(0.95-1.37)^{d}$ & 7 (low) & $\begin{array}{c}\text { Age, sex, Charlson } \\
\text { index, and time of the } \\
\text { swab test }\end{array}$ \\
\hline $\begin{array}{c}\text { Wilcox et al., (2021) } \\
\text { [31] }\end{array}$ & $\begin{array}{l}\text { retrospective } \\
\text { cohort study }\end{array}$ & 2019-2020 & rt-PCR & England & 6921 & $372 / 2613$ & $553 / 4308$ & $0.76(0.64-0.90)$ & 8 (low) & $\begin{array}{c}\text { Age, sex, BMI, } \\
\text { socioeconomic status, } \\
\text { smoking status, frailty } \\
\text { score, comorbidities, } \\
\text { and the number of } \\
\text { prescribed } \\
\text { medications }\end{array}$ \\
\hline
\end{tabular}

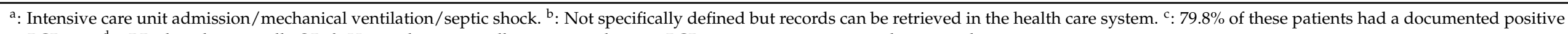
rt-PCR test. ${ }^{d}$ : aRR, the others are all aOR. ${ }^{e}$ : Hospitalization or all-cause mortality. rt-PCR, reverse transcription-polymerase chain reaction. 

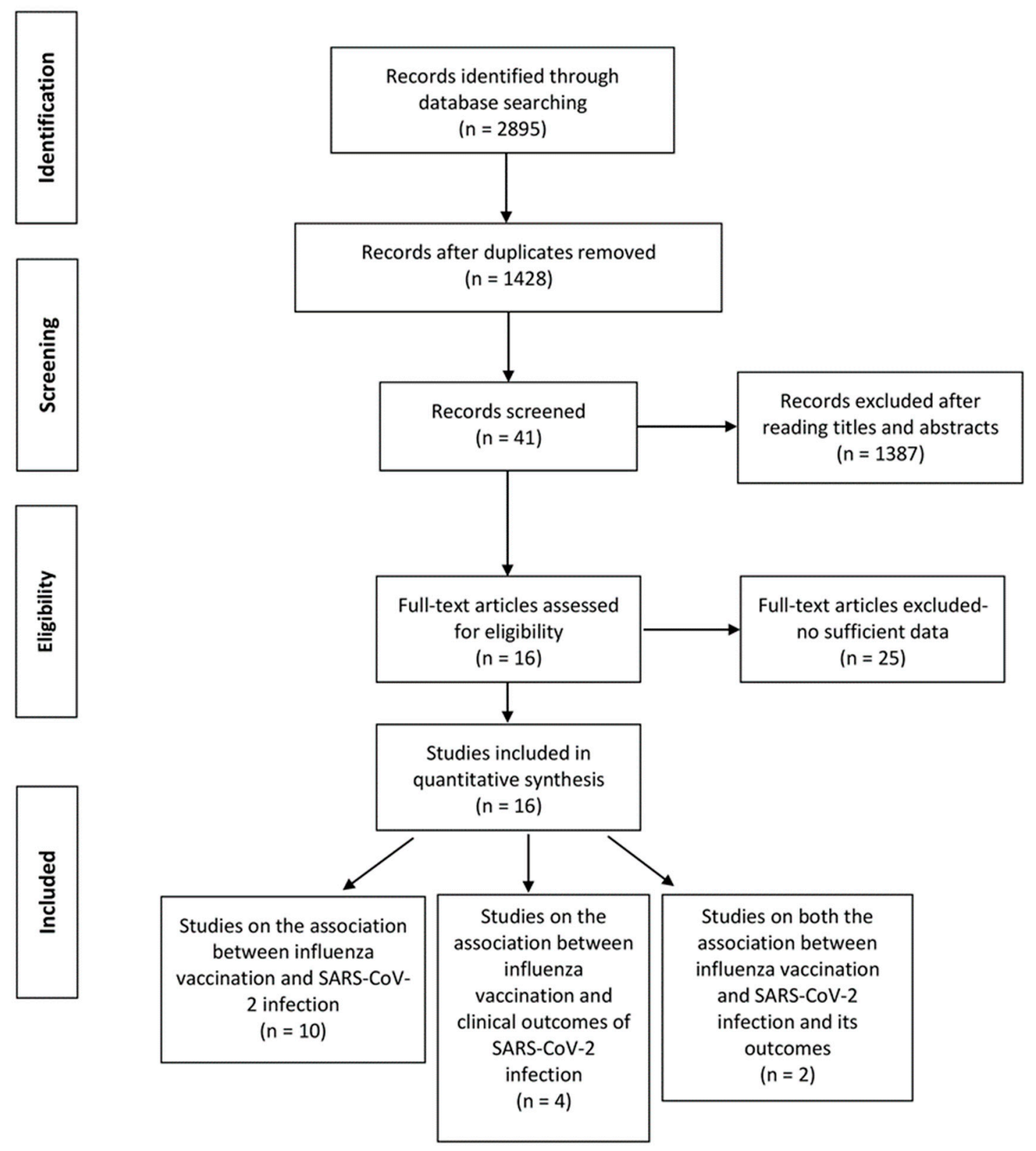

Figure 1. PRISMA flow diagram of the study selection procedure.

\subsection{The Association between Influenza Vaccination and COVID-19 and Its Outcomes}

The association between influenza vaccination and SARS-CoV-2 infection is presented in Figure 2, Table 3 and Supplementary Table S1. Influenza vaccination was shown to be associated with a lower risk of SARS-CoV-2 infection in both models (fixed effects model: pooled adjusted OR: 0.86, 95\%CI: 0.81-0.91; random effects model: pooled adjusted OR: 0.86, 95\%CI: 0.79-0.94). 
A

Study $\quad$ Adjusted $\%$

ID

OR $(95 \% \mathrm{Cl}) \quad$ Weight

\begin{tabular}{|c|c|c|}
\hline Kissling E, et al. (2021) & $\rightarrow$ & $0.93(0.66,1.32) 2.77$ \\
\hline Ragni $P$, et al. (2020) & $\rightarrow$ & $0.89(0.80,0.99) 29.26$ \\
\hline Belingheri $\mathrm{M}$, et al (2020) & -1 & $0.41(0.07,2.39) 0.11$ \\
\hline Vila-Córcoles A, et al. (2020) & $\longrightarrow$ & $0.63(0.43,0.92) 2.30$ \\
\hline Vila-Córcoles A, et al. (2020) & -1 & $1.02(0.79,1.32) 5.04$ \\
\hline Martínez-Baz I, et al. (2020) & $\rightarrow$ & $1.03(0.83,1.27) 7.34$ \\
\hline Noale M, et al. (2020) & $\rightarrow$ & $0.89(0.78,1.01) 19.90$ \\
\hline Green I, et al. (2020) & $\rightarrow-$ & $0.79(0.67,0.98) 9.19$ \\
\hline Conlon A, et al. (2021) & $\rightarrow$ & $0.76(0.68,0.86) 24.09$ \\
\hline Overall (I-squared $=41.1 \%, p=0.094)$ & 0 & $0.86(0.81,0.91) 100.00$ \\
\hline
\end{tabular}

B

$\begin{array}{lll}\text { Study } & \text { Adjusted } & \% \\ \text { ID } & \text { OR }(95 \% \mathrm{Cl}) & \text { Weight }\end{array}$

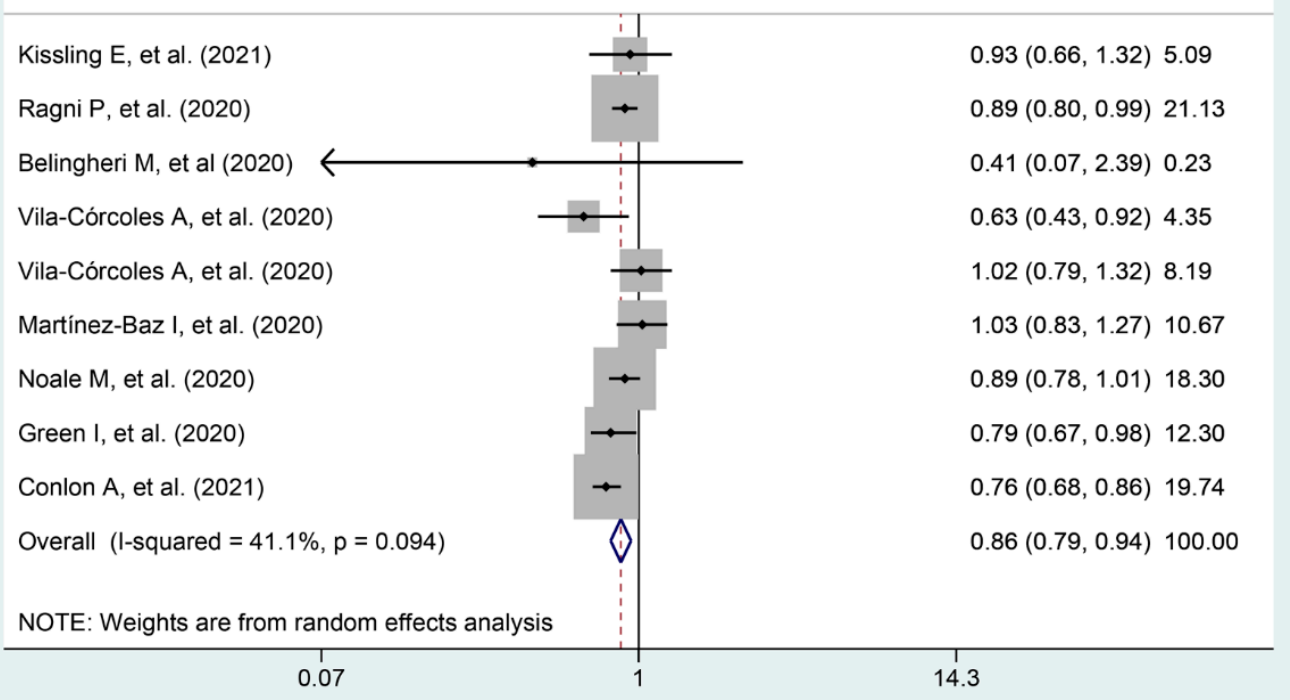

Figure 2. Forest plots for the association between influenza vaccination and SARS-CoV-2 infection: (A) adjusted OR by fixed effects model (B) adjusted OR by random effects model. 
Table 3. Summary of the overall association between influenza vaccination and SARS-CoV-2 infection and clinical outcomes.

\begin{tabular}{|c|c|c|c|c|c|}
\hline \multirow{2}{*}{ Outcomes } & \multirow{2}{*}{ Number of Studies } & \multirow{2}{*}{$I^{2}$ Value (\%) } & \multirow{2}{*}{$p$ Value } & \multicolumn{2}{|c|}{ Adjusted Estimates a $(95 \% \mathrm{CI})$} \\
\hline & & & & Fixed Effects Model & Random Effects Model \\
\hline SARS-CoV-2 infection & 9 & 41.1 & 0.09 & $0.86(0.81-0.91)$ & $0.86(0.79-0.94)$ \\
\hline Intensive care & 2 & 68.2 & 0.08 & $0.93(0.87-0.99)$ & $0.63(0.22-1.81)$ \\
\hline Hospitalization & 3 & 87.6 & $<0.01$ & $0.84(0.75-0.93)$ & $0.74(0.51-1.06)$ \\
\hline Mortality & 3 & 82.5 & $<0.01$ & $0.86(0.81-0.93)$ & $0.89(0.73-1.09)$ \\
\hline
\end{tabular}

a: Adjusted OR or adjusted RR.

The association between influenza vaccination and COVID-19 outcomes are presented in Table 3 and Supplementary Table S1. The association between influenza vaccination and intensive care (adjusted OR: 0.63 , 95\%CI: 0.22-1.81), hospitalization (adjusted OR: 0.74, 95\%CI: 0.51-1.06), or mortality (adjusted OR: 0.89, 95\%CI: 0.73-1.09) among COVID-19 patients was not statistically significant by random effects model, while results by fixed effects model was somehow significant. This may be due to the substantial heterogeneity between the small number of studies (2-3 studies) and participants involved in each outcome.

\subsection{Subgroup Analysis}

Given the heterogeneity among the outcomes of the association between influenza vaccination and SARS-CoV-2 infection (Figure 2, Table 3), we conducted subgroup analyses by sample sizes, regions, and study designs. The results of subgroup analyses are presented in Figure 3, Supplementary Figure S1, Table 4 and Supplementary Table S2. There was no significant evidence of association stratified by sample sizes or study designs (all $p>0.05$ ). However, there was substantial heterogeneity between the adjusted estimates of studies in Europe (0.90, 95\%CI: 0.84-0.97), America (0.76, 95\%CI: 0.68-0.85), and Asia (0.79, 95\%CI: $0.65-0.96, p=0.03)$.

Owing to the paucity of the included studies on the association between influenza vaccination and any of the COVID-19 outcomes (mortality, hospitalization, and intensive care), planned subgroup analyses were not able to be performed.

Table 4. Subgroup analyses of the association between influenza vaccination and SARS-CoV-2 infection.

\begin{tabular}{|c|c|c|c|c|c|c|c|}
\hline \multirow{2}{*}{$\begin{array}{l}\text { Grouping } \\
\text { Variables }\end{array}$} & \multirow[b]{2}{*}{ No. of Studies } & \multicolumn{3}{|c|}{ Random Effects Model } & \multicolumn{3}{|c|}{ Fixed Effects Model } \\
\hline & & $\begin{array}{l}\text { Adjusted Estimate } \\
\qquad(95 \% \mathrm{CI})\end{array}$ & $I^{2}$ Value $(\%)$ & $p$ Value & $\begin{array}{l}\text { Adjusted Estimate } \\
(95 \% \mathrm{CI})\end{array}$ & $I^{2}$ Value (\%) & $p$ Value \\
\hline Region & 9 & & & $0.04^{\mathrm{a}}$ & & & $0.03^{\mathrm{a}}$ \\
\hline Europe & 7 & $0.91(0.84-0.98)$ & 10.4 & $<0.01^{b}$ & $0.90(0.84-0.97)$ & 10.4 & $<0.01^{b}$ \\
\hline Asia & 1 & $0.79(0.65-0.96)$ & - & - & $0.79(0.65-0.96)$ & - & - \\
\hline America & 1 & $0.76(0.68-0.85)$ & - & - & $0.76(0.68-0.85)$ & - & - \\
\hline Sample size & 9 & & & $0.34^{\mathrm{a}}$ & & & $0.06^{\mathrm{a}}$ \\
\hline $\begin{array}{l}\text { Sample size } \\
<20,000\end{array}$ & 6 & $0.89(0.82-0.97)$ & 13.3 & $0.33^{b}$ & $0.89(0.83-0.96)$ & 13.3 & $0.33^{b}$ \\
\hline $\begin{array}{l}\text { Sample size } \\
\geq 20,000\end{array}$ & 3 & $0.82(0.71-0.96)$ & 52.2 & $0.12^{b}$ & $0.80(0.73-0.88)$ & 52.2 & $0.12^{b}$ \\
\hline Study design & 9 & & & $0.83^{a}$ & & & $0.55^{\mathrm{a}}$ \\
\hline $\begin{array}{l}\text { Case-control } \\
\text { study }\end{array}$ & 2 & $0.89(0.81-0.99)$ & 0.0 & $0.81^{b}$ & $0.89(0.81-0.99)$ & 0.0 & $0.81^{b}$ \\
\hline $\begin{array}{l}\text { Cross-sectional } \\
\text { study }\end{array}$ & 3 & $0.85(0.77-0.95)$ & 0.0 & $0.43^{b}$ & $0.85(0.77-0.95)$ & 0.0 & $0.43^{b}$ \\
\hline Cohort study & 4 & $0.86(0.70-1.05)$ & 71.7 & $0.01^{\mathrm{b}}$ & $0.83(0.75-0.91)$ & 71.7 & $0.01^{\mathrm{b}}$ \\
\hline
\end{tabular}

${ }^{\mathrm{a}}: p$ value for subgroup difference. ${ }^{\mathrm{b}}: p$ value for heterogeneity. 


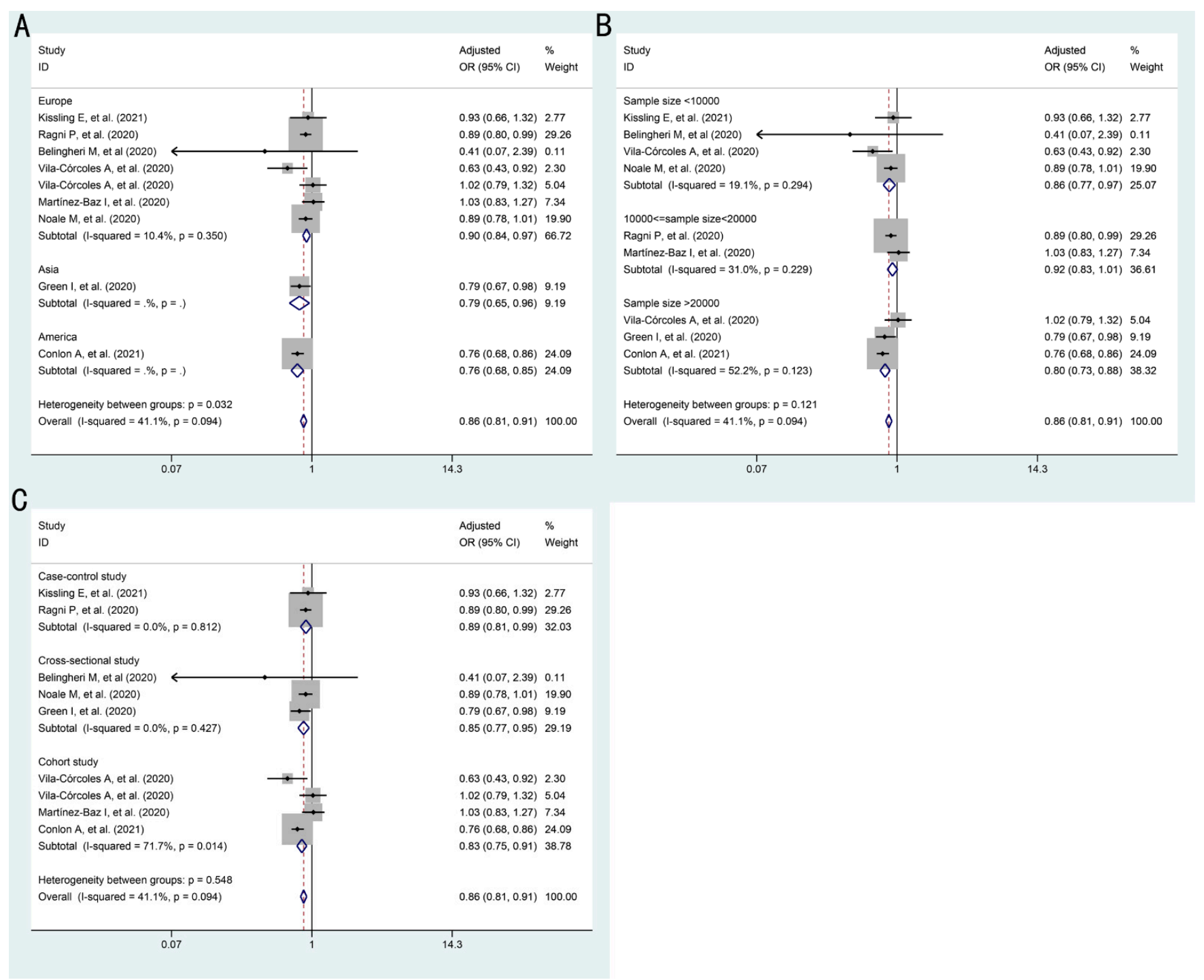

Figure 3. Forest plots for subgroup analysis on the association between influenza vaccination and SARS-CoV-2 infection by fixed effects model: (A) stratified by region (B) stratified by sample size (C) stratified by study design.

\subsection{Publication Bias and Sensitivity Analysis}

In the sensitivity analyses regarding the association between influenza vaccination and SARS-CoV-2 infection, the pooled estimates were consistent when any one of the studies was omitted, which demonstrated the robustness of the results. Sensitivity analyses on the association between influenza vaccination and clinical outcomes among COVID-19 patients were not carried out owing to the sparseness of the included studies.

The summary of the publication bias are presented in Table 5 and Figure 4. Both funnel plots and Egger's tests showed no evidence of publication bias for the pooled estimates and adjusted estimates of the association between influenza vaccination and SARS-CoV-2 infection (all $p>0.05$ ). Neither evidence of publication bias for the association between influenza vaccination and COVID-19 related hospitalization or COVID-19-related mortality were observed (all $p>0.05$ ). 
Table 5. Summary of publication bias on the association between influenza vaccination and SARSCoV-2 infection and clinical outcomes.

\begin{tabular}{ccc}
\hline Outcomes & $\boldsymbol{t}$ Value & $p$ Value \\
\hline SARS-CoV-2 infection & -0.19 & 0.85 \\
Mortality & 0.46 & 0.73 \\
Hospitalization & -0.87 & 0.55 \\
\hline
\end{tabular}

Results from adjusted OR.
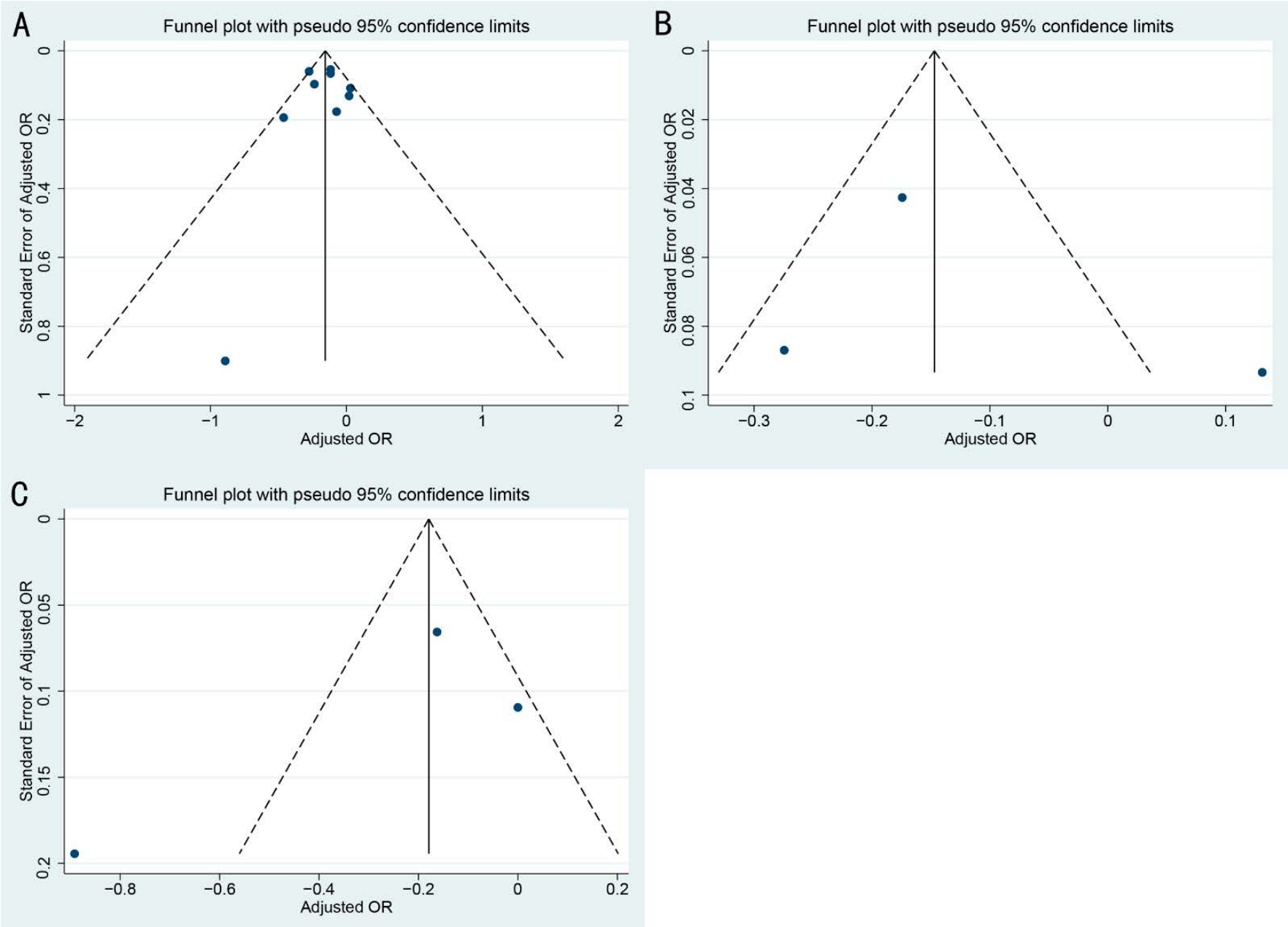

Figure 4. Funnel plots for the associations between influenza vaccination and SARS-CoV-2 infection and clinical outcomes: (A) adjusted OR of SARS-CoV-2 infection (B) mortality (C) hospitalization.

\section{Discussion}

To our best knowledge, this is the first meta-analysis that systematically assessed the association between influenza vaccination and SARS-CoV-2 infection, and the association between influenza vaccination and clinical outcomes of SARS-CoV-2 infection. We ultimately included a total of 16 studies (12 on SARS-CoV-2 infection and six on clinical outcomes of SARS-CoV-2 infection, two on both) that had evaluated the associations. We observed a significant association between influenza vaccination and SARS-CoV-2 infection by pooling the adjusted estimates, while no evidence of the association was found between influenza vaccination and any of the clinical outcomes (hospitalization, mortality, and intensive care) among COVID-19 infected patients.

In the era of the COVID-19 pandemic, simply having licensed vaccines is not enough to achieve global control of COVID-19. Vaccines also need to be globally allocated and 
widely deployed [33]. Currently, only $4.3 \%$ of the global population have received at least one dose of a COVID-19 vaccine [34]. Vulnerable groups, such as the elderly and pregnant women, are usually not specifically included in COVID-19 clinical trials. Meanwhile, considerable mutation of SARS-CoV-2 has occurred since its initial emergence, which may have impact on the effectiveness of current vaccines and should be considered in vaccine design and development [35].

Influenza vaccination is regarded as the most effective measure to prevent influenza and influenza-related complications, especially for high-risk populations [36]. Previous studies suggested that older adults and pregnant women with influenza vaccination had a significantly lower risk of getting laboratory-confirmed influenza (older adults: risk ratio (RR) 0.76, 95\%CI: 0.65-0.90; pregnant women: RR 0.3, 95\% CI: 0.26-0.35) [37,38], which demonstrated relatively high effectiveness of influenza vaccines and highlighted the necessity of influenza vaccination. Restivo et al. [39] reported that influenza vaccine effectiveness was 39\% (95\%CI: 32-46\%) for hospital visits and 57\% (95\%CI: 30-74\%) for hospitalization among children, and the rate was 25\% (95\%CI: 6-40\%) for visits and $14 \%$ (95\%CI: $7-21 \%)$ for hospitalization among older adults. Cheng et al. [40] conducted a meta-analysis that included 29 studies and found that influenza vaccination was associated with a lower risk of overall adversary respiratory outcomes (including asthma, chronic obstructive pulmonary disease, unspecific respiratory diseases, respiratory failure, respiratory infections, pneumonia, and respiratory mortality) in the group aged over 65, from which significant associations were detected between influenza vaccination and pneumonia (aRR 0.79, 95\% CI: $0.65-0.95$ ) and respiratory mortality (aRR 0.79, $95 \%$ CI: $0.67-0.92$ ). These results showed that influenza vaccination was effective at protecting vulnerable populations from influenza and its complications.

Due to the constant slight changes that influenza viruses undergo each season, influenza vaccines are required to be modified annually to maintain their effectiveness. Though influenza vaccination has been recommended by the WHO and other global organizations, annual influenza vaccine coverage remains to be relatively low in vulnerable populations. The overall influenza vaccination uptake rate among subjects with highrisk chronic conditions in Spain in 2017 was only $40.1 \%$ and decreased significantly from 2014 [41]. Though the rate among American children aged from 6 months to 17 years old increased from $16.70 \%$ during $2004 / 2005$ to $49.43 \%$ during $2015 / 2016$, it was still far below the U.S. Healthy People 2020 target of $70 \%$ annual influenza vaccination coverage among children [42]. In France, influenza vaccine coverage among pregnant women was only $7.4 \%$ in 2015/2016 season [43]. Effective interventions and tailored measures should be conducted to promote influenza vaccination and reduce vaccine hesitancy among high-risk populations.

Apart from playing an important role in influenza prevention, seasonal influenza vaccination is considered to have additional value in the strained period of COVID-19 pandemic. Influenza vaccination can reduce influenza-related hospital visits, thereby largely reducing the potential risk of respiratory infectious diseases, such as COVID-19, alleviating the burden of health care systems and saving medical resources for the treatment of other severe diseases [44]. It is also believed that being protected against influenza by vaccination enhances the accuracy of COVID-19 diagnosis and the specificity of COVID-19 surveillance [45].

In our study, we found that the influenza vaccination was associated with a lower risk of SARS-CoV-2 infection. One possible explanation was that those who received influenza vaccinations in the past seasons tended to pay more attention to their health status, thus they might have been more compliant with COVID-19 prevention measures, such as social distancing and wearing masks, which reduced their potential risk of infection. In addition, influenza vaccination could reduce the risk of influenza, which reduces the possibility of hospital visits and the risk of SARS-CoV-2 infection in high-risk areas, such as hospitals. Another possible theory that could explain influenza vaccine's protective effect against COVID-19 is the trained immunity process. Influenza vaccines may induce non-specific 
activation of innate immune cells (e.g., natural killer cells) by increasing proinflammatory cytokine production, thereby triggering the non-specific protective effects against the diseases caused by heterologous viruses [46,47]. Such a mechanism has been demonstrated in Bacillus Calmette-Guérin (BCG) vaccine's protective effective against malaria [48]. Accelerated natural killer cells and monocyte activation that correlated with reduced parasitemia was observed in the BCG vaccinated volunteers, which was consistent with the possibility of trained immunity. Likewise, influenza vaccination might be associated with a lower risk of COVID-19 via trained immunity. The underlying mechanism of the potential association between influenza vaccination and SARS-CoV-2 infection awaits further exploration.

Although we observed no evidence of a significant association between influenza vaccination and the lower risk of clinical outcomes among COVID-19 patients, Hui et al. [49] found that exposure of influenza A virus may upregulate the angiotensin-converting enzyme 2 (ACE2) receptors in alveolar epithelial cells, which facilitates SARS-CoV-2 virus to enter into alveolar epithelial cells and worsen clinical outcomes of SARS-CoV-2 infection. However, such effect was not observed in human macrophages. Bai et al. [3] found that influenza A virus promotes the infectivity of SARS-CoV-2 virus. The co-infection of influenza A virus and SARS-CoV-2 virus in mice resulted in increased SARS-CoV-2 viral load and more severe lung damage. Therefore, influenza vaccination may have a positive effect on better clinical outcomes of SARS-CoV-2 infection. More conclusive evidence is needed in the future.

In the subgroup analysis, statistics indicated that regions might be the potential sources of heterogeneity for the association between influenza vaccination and SARS-CoV2 infection. The regional difference of the association between influenza vaccination and SARS-CoV-2 infection might result from various factors, including the diverse characteristics and immunity of the populations, the difference in the toxicity of SARS-CoV-2 viruses and dominant strains, and the efforts of COVID-19 prevention and control across regions.

The limitations in this study are listed as follows. First, subgroup analyses and sensitivity analyses on the association between influenza vaccination and the clinical outcomes of SARS-CoV-2 infection were not performed due to the limited number of studies. Similarly, publication bias was not adequately assessed. More relevant studies are needed to provide more precise pooled estimates. Second, only observational studies were available and included in our meta-analysis, so that the evidence regarding the intervention was not as strong as randomized controlled trials [50]. Nonetheless, this meta-analysis was performed strictly in accordance with the MOOSE guideline. Studies included in this metaanalysis took certain measures to minimize potential biases in selection and confounders, and all showed low to moderate risk of biases. Third, the exact influenza vaccination seasons and the confirmation of COVID-19 patients in some of the included studies were not specifically defined. Age groups and types of influenza viruses were not able to be used as grouping variables in subgroup analyses for lack of sufficient feasible studies with clear definitions and classifications. Additionally, studies included in the meta-analysis were all conducted before December 2020 when COVID-19 vaccines were not licensed yet. Some participants may have entered COVID-19 vaccine clinical trials and received vaccines, but were not reported in the studies, which may have impact on our analysis. However, the proportion of volunteers in COVID-19 vaccine trials could be very low and had little effects on our study. Last it was not possible to fully evaluate the possibility of overlapping participants among the included studies due to limited data. Nonetheless, this is the first meta-analysis that systematically assessed the association between influenza vaccination and COVID-19 and its outcomes, which could provide evidence-based medicine basis for the prevention of COVID-19 and influenza vaccination promotion.

\section{Conclusions}

This meta-analysis indicates that the influenza vaccination is associated with a lower risk of SARS-CoV-2 infection, while its association with clinical outcomes (mortality, hospi- 
talization, and intensive care) of SARS-CoV-2 infection is not found. In the dual epidemics of the COVID-19 pandemic and influenza, it is especially crucial for policymakers to implement strategies aimed at promoting influenza vaccination, and that relevant public health campaigns and policy initiatives should be put in place to inform people of influenza vaccination benefits for the prevention and control of COVID-19. More evidence-based studies are urgently warranted to explore the association between influenza vaccination and SARS-CoV-2 infection and its outcomes, along with more in-depth research needed to further explain the underlying mechanisms for the associations.

Supplementary Materials: The following are available online at https:/ / www.mdpi.com/article/10 .3390 /vaccines 9050529 / s1, Table S1: Summary of the overall association between influenza vaccination and SARS-CoV-2 infection and clinical outcomes by crude OR; Table S2: Subgroup analyses of the association between influenza vaccination and SARS-CoV-2 infection by crude OR; Figure S1: Forest plots for subgroup analysis on the association between influenza vaccination and SARS-CoV-2 infection by random effects model: (A) stratified by region (B) stratified by sample size (C) stratified by study design.

Author Contributions: Conceptualization, R.W. and J.L.; methodology, R.W. and J.L.; software, R.W.; validation, R.W., J.L. and M.L.; formal analysis, R.W.; data curation, R.W.; writing-original draft preparation, R.W.; writing-review and editing, R.W., M.L., and J.L.; visualization, R.W.; supervision, J.L.; funding acquisition, J.L. All authors have read and agreed to the published version of the manuscript.

Funding: This work was funded by the National Key Research and Development Project of China [grant numbers 2020YFC0846300, 2019YFC1710301]; the National Science and Technology Key Projects on Prevention and Treatment of Major infectious disease of China (grant number 2020ZX10001002); and the National Natural Science Foundation of China (grant numbers 71874003, 71934002, 81703240).

Data Availability Statement: Data are available from the corresponding author by request.

Conflicts of Interest: The authors declare no conflict of interest.

\section{References}

1. World Health Organization. Weekly Epidemiological Update on COVID-19. Available online: https://www.who.int/ publications/m/item/weekly-epidemiological-update-on-covid-19 (accessed on 10 April 2021).

2. Nelson, M.I.; Tan, Y.; Ghedin, E.; Wentworth, D.E.; St George, K.; Edelman, L.; Beck, E.T.; Fan, J.; Lam, T.T.-Y.; Kumar, S.; et al. Phylogeography of the spring and fall waves of the H1N1/09 pandemic influenza virus in the United States. J. Virol. 2011, 85, 828-834. [CrossRef]

3. Bai, L.; Zhao, Y.; Dong, J.; Liang, S.; Guo, M.; Liu, X.; Wang, X.; Huang, Z.; Sun, X.; Zhang, Z.; et al. Coinfection with influenza A virus enhances SARS-CoV-2 infectivity. Cell. Res. 2021, 31, 395-403. [CrossRef] [PubMed]

4. Xiang, X.; Wang, Z.H.; Ye, L.L.; He, X.L.; Wei, X.S.; Ma, Y.L.; Li, H.; Chen, L.; Wang, X.R.; Zhou, Q. Co-infection of SARS-COV-2 and Influenza A Virus: A Case Series and Fast Review. Curr. Med. Sci. 2021, 41, 51-57. [CrossRef] [PubMed]

5. Konala, V.M.; Adapa, S.; Gayam, V.; Naramala, S.; Daggubati, S.R.; Kammari, C.B.; Chenna, A. Co-infection with Influenza A and COVID-19. Eur. J. Case. Rep. Intern. Med. 2020, 7, 001656. [PubMed]

6. Buchy, P.; Badur, S. Who and when to vaccinate against influenza. Int. J. Infect. Dis. 2020, 93, 375-387. [CrossRef]

7. Liu, Y.; Morgenstern, C.; Kelly, J.; Lowe, R.; Jit, M. The impact of non-pharmaceutical interventions on SARS-CoV-2 transmission across 130 countries and territories. BMC Med. 2021, 19, 40. [CrossRef]

8. Moore, J.P.; Klasse, P.J. COVID-19 Vaccines: “Warp Speed” Needs Mind Melds, Not Warped Minds. J. Virol. 2020, 94, e01083-20. [CrossRef]

9. Wolff, G.G. Influenza vaccination and respiratory virus interference among Department of Defense personnel during the 2017-2018 influenza season. Vaccine 2020, 38, 350-354. [CrossRef] [PubMed]

10. Fink, G.; Orlova-Fink, N.; Schindler, T.; Grisi, S.; Ferrer, A.P.S.; Daubenberger, C.; Brentani, A. Inactivated trivalent influenza vaccination is associated with lower mortality among patients with COVID-19 in Brazil. BMJ Evid. Based Med. 2020, in press. [CrossRef]

11. Del Riccio, M.; Lorini, C.; Bonaccorsi, G.; Paget, J.; Caini, S. The Association between Influenza Vaccination and the Risk of SARS-CoV-2 Infection, Severe Illness, and Death: A Systematic Review of the Literature. Int. J. Environ. Res. Public Health 2020, 17, 7870. [CrossRef]

12. Cocco, P.; Meloni, F.; Coratza, A.; Schirru, D.; Campagna, M.; De Matteis, S. Vaccination against seasonal influenza and socioeconomic and environmental factors as determinants of the geographic variation of COVID-19 incidence and mortality in the Italian elderly. Prev. Med. 2021, 143, 106351. [CrossRef] [PubMed] 
13. Amato, M.; Werba, J.P.; Frigerio, B.; Coggi, D.; Sansaro, D.; Ravani, A.; Ferrante, P.; Veglia, F.; Tremoli, E.; Baldassarre, D. Relationship between Influenza Vaccination Coverage Rate and COVID-19 Outbreak: An Italian Ecological Study. Vaccines 2020, 8, 535. [CrossRef] [PubMed]

14. Arokiaraj, M.C. Considering Interim Interventions to Control COVID-19 Associated Morbidity and Mortality-Perspectives. Front. Public Health 2020, 8, 444. [CrossRef] [PubMed]

15. Marín-Hernández, D.; Schwartz, R.E.; Nixon, D.F. Epidemiological evidence for association between higher influenza vaccine uptake in the elderly and lower COVID-19 deaths in Italy. J. Med. Virol. 2021, 93, 64-65. [CrossRef]

16. Martínez-Baz, I.; Trobajo-Sanmartín, C.; Arregui, I.; Navascués, A.; Adelantado, M.; Indurain, J.; Fresán, U.; Ezpeleta, C.; Castilla, J. Influenza Vaccination and Risk of SARS-CoV-2 Infection in a Cohort of Health Workers. Vaccines 2020, 8, 611. [CrossRef]

17. De la Cruz Conty, M.L.; Encinas Pardilla, M.B.; Garcia Sanchez, M.; Gonzalez Rodriguez, L.; Muner-Hernando, M.L.; Royuela Vicente, A.; Pintado Recarte, P.; Martinez Varea, A.; Martinez Diago, C.; Cruz Melguizo, S.; et al. Impact of Recommended Maternal Vaccination Programs on the Clinical Presentation of SARS-CoV-2 Infection: A Prospective Observational Study. Vaccines 2021, 9, 31. [CrossRef]

18. Kissling, E.; Hooiveld, M.; Brytting, M.; Vilcu, A.M.; de Lange, M.; Martínez-Baz, I.; Sigerson, D.; Enkirch, T.; Belhillil, S.; Meijer, A.; et al. Absence of association between 2019-20 influenza vaccination and COVID-19: Results of the European I-MOVE-COVID-19 primary care project, March-August 2020. Influenza Other Respir. Viruses in press.

19. Wells, G.A.; Shea, B.; O'Connell, D.a.; Peterson, J.; Welch, V.; Losos, M.; Tugwell, P. The Newcastle-Ottawa Scale (NOS) for Assessing the Quality of Nonrandomised Studies in Meta-Analyses. Available online: http://www.ohri.ca/programs/clinical_ epidemiology/oxford.asp (accessed on 1 April 2021).

20. Rostom, A.; Dube, C.; Cranney, A. Rockville (MD): Agency for Healthcare Research and Quality (US). Available online: https: //www.ncbi.nlm.nih.gov/books/NBK35156/ (accessed on 1 April 2021).

21. Massoudi, N.; Mohit, B. A Case-Control Study of the 2019 Influenza Vaccine and Incidence of COVID-19 among Healthcare Workers. J. Clin. Immunol. 2021, 41, 324-334. [CrossRef]

22. Ragni, P.; Marino, M.; Formisano, D.; Bisaccia, E.; Scaltriti, S.; Bedeschi, E.; Grilli, R. Association between Exposure to Influenza Vaccination and COVID-19 Diagnosis and Outcomes. Vaccines 2020, 8, 675. [CrossRef]

23. Belingheri, M.; Paladino, M.E.; Latocca, R.; De Vito, G.; Riva, M.A. Association between seasonal flu vaccination and COVID-19 among healthcare workers. Occup. Med. 2020, 70, 665-671. [CrossRef]

24. Vila-Córcoles, Á.; Ochoa-Gondar, O.; Torrente-Fraga, C.; Vila-Rovira, Á.; Satué-Gracia, E.; Hospital-Guardiola, I.; de DiegoCabanes, C.; Gómez-Bertomeu, F.; Basora-Gallisà, J. Evaluation of incidence and risk profile for suffering Covid-19 infection by underlying conditions among middle-aged and older adults in Tarragona. Rev. Esp. Salud. Publica 2020, 94, e202006065.

25. Vila-Córcoles, A.; Ochoa-Gondar, O.; Satué-Gracia, E.M.; Torrente-Fraga, C.; Gomez-Bertomeu, F.; Vila-Rovira, A.; HospitalGuardiola, I.; de Diego-Cabanes, C.; Bejarano-Romero, F.; Basora-Gallisà, J. Influence of prior comorbidities and chronic medications use on the risk of COVID-19 in adults: A population-based cohort study in Tarragona, Spain. BMJ Open 2020, 10, e041577. [CrossRef]

26. Pawlowski, C.; Puranik, A.; Bandi, H.; Venkatakrishnan, A.J.; Agarwal, V.; Kennedy, R.; O’Horo, J.C.; Gores, G.J.; Williams, A.W.; Halamka, J.; et al. Exploratory analysis of immunization records highlights decreased SARS-CoV-2 rates in individuals with recent non-COVID-19 vaccinations. Sci. Rep. 2021, 11, 4741. [CrossRef] [PubMed]

27. Jehi, L.; Ji, X.; Milinovich, A.; Erzurum, S.; Rubin, B.P.; Gordon, S.; Young, J.B.; Kattan, M.W. Individualizing Risk Prediction for Positive Coronavirus Disease 2019 Testing: Results From 11,672 Patients. Chest 2020, 158, 1364-1375. [CrossRef] [PubMed]

28. Noale, M.; Trevisan, C.; Maggi, S.; Antonelli Incalzi, R.; Pedone, C.; Di Bari, M.; Adorni, F.; Jesuthasan, N.; Sojic, A.; Galli, M.; et al. The Association between Influenza and Pneumococcal Vaccinations and SARS-Cov-2 Infection: Data from the EPICOVID19 Web-Based Survey. Vaccines 2020, 8, 471. [CrossRef] [PubMed]

29. Green, I.; Ashkenazi, S.; Merzon, E.; Vinker, S.; Golan-Cohen, A. The association of previous influenza vaccination and coronavirus disease-2019. Hum. Vaccines Immunother. in press.

30. Conlon, A.; Ashur, C.; Washer, L.; Eagle, K.A.; Hofmann Bowman, M.A. Impact of the influenza vaccine on COVID-19 infection rates and severity. Am. J. Infect. Control 2021, in press. [CrossRef] [PubMed]

31. Wilcox, C.R.; Islam, N.; Dambha-Miller, H. Association between influenza vaccination and hospitalisation or all-cause mortality in people with COVID-19: A retrospective cohort study. BMJ Open. Respir. Res. 2021, 8, e000857. [CrossRef]

32. Yang, M.J.; Rooks, B.J.; Le, T.T.; Santiago, I.O., 3rd; Diamond, J.; Dorsey, N.L.; Mainous, A.G., 3rd. Influenza Vaccination and Hospitalizations among COVID-19 Infected Adults. J. Am. Board Fam. Med. 2021, 34, S179-S182. [CrossRef]

33. Wouters, O.J.; Shadlen, K.C.; Salcher-Konrad, M.; Pollard, A.J.; Larson, H.J.; Teerawattananon, Y.; Jit, M. Challenges in ensuring global access to COVID-19 vaccines: Production, affordability, allocation, and deployment. Lancet 2021, 397, 1023-1034. [CrossRef]

34. Deployment of COVID-19 Vaccines. Available online: https:/ / en.wikipedia.org/wiki/Deployment_of_COVID-19_vaccines\# cite_note-world-total-18 (accessed on 10 April 2021).

35. Grubaugh, N.D.; Hanage, W.P.; Rasmussen, A.L. Making Sense of Mutation: What D614G Means for the COVID-19 Pandemic Remains Unclear. Cell 2020, 182, 794-795. [CrossRef] [PubMed]

36. Wang, Q.; Yue, N.; Zheng, M.; Wang, D.; Duan, C.; Yu, X.; Zhang, X.; Bao, C.; Jin, H. Influenza vaccination coverage of population and the factors influencing influenza vaccination in mainland China: A meta-analysis. Vaccine 2018, 36, 7262-7269. [CrossRef] 
37. Quach, T.H.T.; Mallis, N.A.; Cordero, J.F. Influenza Vaccine Efficacy and Effectiveness in Pregnant Women: Systematic Review and Meta-analysis. Matern. Child Health J. 2020, 24, 229-240. [CrossRef] [PubMed]

38. Wilkinson, K.; Wei, Y.; Szwajcer, A.; Rabbani, R.; Zarychanski, R.; Abou-Setta, A.M.; Mahmud, S.M. Efficacy and safety of high-dose influenza vaccine in elderly adults: A systematic review and meta-analysis. Vaccine 2017, 35, 2775-2780. [CrossRef]

39. Restivo, V.; Costantino, C.; Bono, S.; Maniglia, M.; Marchese, V.; Ventura, G.; Casuccio, A.; Tramuto, F.; Vitale, F. Influenza vaccine effectiveness among high-risk groups: A systematic literature review and meta-analysis of case-control and cohort studies. Hum. Vaccines Immunother. 2018, 14, 724-735. [CrossRef] [PubMed]

40. Cheng, Y.; Cao, X.; Cao, Z.; Xu, C.; Sun, L.; Gao, Y.; Wang, Y.; Li, S.; Wu, C.; Li, X.; et al. Effects of influenza vaccination on the risk of cardiovascular and respiratory diseases and all-cause mortality. Ageing Res. Rev. 2020, 62, 101124. [CrossRef] [PubMed]

41. Martinez-Huedo, M.A.; Lopez-De-Andrés, A.; Mora-Zamorano, E.; Hernández-Barrera, V.; Jiménez-Trujillo, I.; Zamorano-Leon, J.J.; Jiménez-García, R. Decreasing influenza vaccine coverage among adults with high-risk chronic diseases in Spain from 2014 to 2017. Hum. Vaccines Immunother. 2020, 16, 95-99. [CrossRef]

42. Tian, C.; Wang, H.; Wang, W.; Luo, X. Influenza vaccination coverage among US children from 2004/2005 to 2015/2016. J. Public Health 2018, 41, e62-e69. [CrossRef]

43. Descamps, A.; Launay, O.; Bonnet, C.; Blondel, B. Seasonal influenza vaccine uptake and vaccine refusal among pregnant women in France: Results from a national survey. Hum. Vaccines Immunother. 2020, 16, 1093-1100. [CrossRef]

44. Paget, J.; Caini, S.; Cowling, B.; Esposito, S.; Falsey, A.R.; Gentile, A.; Kyncl, J.; MacIntyre, C.; Pitman, R.; Lina, B. The impact of influenza vaccination on the COVID-19 pandemic? Evidence and lessons for public health policies. Vaccine 2020, 38, 6485-6486. [CrossRef]

45. Thindwa, D.; Garcia Quesada, M.; Liu, Y.; Bennett, J.; Cohen, C.; Knoll, M.D.; von Gottberg, A.; Hayford, K.; Flasche, S. Use of seasonal influenza and pneumococcal polysaccharide vaccines in older adults to reduce COVID-19 mortality. Vaccine 2020, 38, 5398-5401. [CrossRef] [PubMed]

46. Netea, M.G.; Domínguez-Andrés, J.; Barreiro, L.B.; Chavakis, T.; Divangahi, M.; Fuchs, E.; Joosten, L.A.B.; van der Meer, J.W.M.; Mhlanga, M.M.; Mulder, W.J.M.; et al. Defining trained immunity and its role in health and disease. Nat. Rev. Immunol. 2020, 20, 375-388. [CrossRef]

47. Kleinnijenhuis, J.; Quintin, J.; Preijers, F.; Joosten, L.A.; Jacobs, C.; Xavier, R.J.; van der Meer, J.W.; van Crevel, R.; Netea, M.G. BCG-induced trained immunity in NK cells: Role for non-specific protection to infection. Clin. Immunol. 2014, 155, $213-219$. [CrossRef] [PubMed]

48. Walk, J.; de Bree, L.C.J.; Graumans, W.; Stoter, R.; van Gemert, G.J.; van de Vegte-Bolmer, M.; Teelen, K.; Hermsen, C.C.; Arts, R.J.W.; Behet, M.C.; et al. Outcomes of controlled human malaria infection after BCG vaccination. Nat. Commun. 2019, 10, 874. [CrossRef] [PubMed]

49. Hui, K.P.Y.; Cheung, M.C.; Perera, R.; Ng, K.C.; Bui, C.H.T.; Ho, J.C.W.; Ng, M.M.T.; Kuok, D.I.T.; Shih, K.C.; Tsao, S.W.; et al. Tropism, replication competence, and innate immune responses of the coronavirus SARS-CoV-2 in human respiratory tract and conjunctiva: An analysis in ex-vivo and in-vitro cultures. Lancet Respir. Med. 2020, 8, 687-695. [CrossRef]

50. Stroup, D.F.; Berlin, J.A.; Morton, S.C.; Olkin, I.; Williamson, G.D.; Rennie, D.; Moher, D.; Becker, B.J.; Sipe, T.A.; Thacker, S.B. Meta-analysis of observational studies in epidemiology: A proposal for reporting. Meta-analysis Of Observational Studies in Epidemiology (MOOSE) group. JAMA 2000, 283, 2008-2012. [CrossRef] 